\title{
Sense of Coherence in People with Cerebral Palsy in Greece
}

\author{
Vasiliki Kontou1, Garyfalia Charitaki², Spyridon-Georgios Soulis ${ }^{3}$ \\ ${ }^{1}$ Cass School of Education, AKMI Metropolitan College in Collaboration with University of East London, Athens, Greece \\ ${ }^{2}$ Hellenic Open University, Patras, Greece \\ ${ }^{3}$ Department of Primary Education, University of Ioannina, Ioannina, Greece \\ Email: vasia_kontou@hotmail.com, charitaki.garyfalia@ac.eap.gr, soulis.spyridon@ac.eap.gr
}

How to cite this paper: Kontou, V., Charitaki, G., \& Soulis, S.-G. (2018). Sense of Coherence in People with Cerebral Palsy in Greece. Psychology, 9, 608-622. https://doi.org/10.4236/psych.2018.94038

Received: February 21, 2018

Accepted: April 10, 2018

Published: April 13, 2018

Copyright (C) 2018 by authors and Scientific Research Publishing Inc. This work is licensed under the Creative Commons Attribution International License (CC BY 4.0).

http://creativecommons.org/licenses/by/4.0/ cc) (†) Open Access

\begin{abstract}
Purpose: The basic aim of this research was to evaluate the Sense of Coherence (SOC) in people with Cerebral Palsy in Greece. Also, the correlation of SOC with their Quality of Life was investigated. Method: For the purposes of the research, a mixed methodological approach was chosen. The Sense of Coherence (SOC) was administered to 37 people with Cerebral Palsy. Semi-structured interviews at Special Educators were also conducted and observation of the participants was carried out in order to collect sufficient data both for their Sense of Coherence and Quality of Life. Results: The results depict high scores of sense of coherence in people with cerebral palsy, which is in significant correlation to their quality of life. It appeared that there was no statistically significant difference between them $(\mathrm{Z}=-0.736$, $p$-value $=0.462)$ and the significance level was determined at a $=5 \%$. Also, there was no statistically significant differentiation in SOC-score between people with different types of cerebral palsy $(\mathrm{F}=0.258, p$-value $=0.933)$, with the significance level at $5 \%$. Conclusion: As a conclusion, people with Cerebral Palsy are satisfied with their everyday life. They can control their feelings and they can cope with unknown situations. They experience pleasant feelings and do not easily experience the emotion of disappointment.
\end{abstract}

\section{Keywords}

Cerebral Palsy, Sense of Coherence, Quality of Life, Intellectual Disability

\section{Introduction}

According to the international bibliography (WHO, 1993, Koman et al., 2003, Budden, 2005, Rosenbaum et al., 2007), cerebral palsy is a brain disorder that 
causes difficulties in movement, body position and balance and quite often sensory and cognitive dysfunctions. Incidents occurring before birth, during birth or after birth can be responsible for the appearance of cerebral palsy (Leviton et al., 2010).

Many researchers believe that the quality of life of people with cerebral palsy highly depends on their self-satisfaction. Their disability is more obvious compared to people with different disorders and therefore they have to deal with social exclusion (Spetsiotis \& Stathopoulos, 2006). They blame themselves for the way society treats them and they suffer from emotional and psychological disorders (Turner, 1990). As a result, people with cerebral palsy are expected to have low self-esteem and experience feelings of disappointment with their life, while in reality, their quality of life can be much better (Kroustalakis, 2005).

\section{Theoretical Background}

Almost 2-2.5/1000 babies are born with cerebral palsy and that is why cerebral palsy is considered to be the most common disability in infants and children. An important parameter of its high rates of incidence is that it is impossible to be identified through prenatal screening (Stanley et al., 2000). According to Bobath \& Bobath (1975) and Budden (2005), cerebral palsy is classified in monoplegia, hemiplegia, diplegia, triplegia, quadriplegia and paraplegia. In monoplegia only one limb is involved, usually one hand. This type of cerebral palsy is the most uncommon, together with triplegia and paraplegia, and in most cases it turns into hemiplegia. In hemiplegia, only one side of the body, left or right, seems to have difficulties in movement, in triplegia three of four limbs are involved and in paraplegia only the lower limbs. On the other hand, diplegia is the most common type of cerebral palsy $(30 \%-40 \%)$ and it is directly correlated to premature birth. In diplegic cerebral palsy, the lower limbs are more involved than the upper limbs. However, people with diplegia are usually able to control their head movement and they do not seem to have speech problems, while the commonest deficits associated with diplegia are visual disturbances, such as strabismus. Finally, quadriplegic cerebral palsy is the most severe type, as the whole body is affected, with the upper limbs being usually more involved than the lower limbs. People with quadriplegia do not have any control of their head movement. They often have speech and vision problems, difficulties in swallowing and seizures. Although, the most severe deficit associated with quadriplegic cerebral palsy is mental retardation (Sankar \& Mundkur, 2005).

In most cases of cerebral palsy there are associated deficits that cause even more difficulties to those people, than their motor problems (Kosmetatou, 2010). Intellectual Disability is observed in 30\% - 60\% of all cases (Evans et al., 1990), which is also followed by speech and language disorders. Visual impairments, such as strabismus, amblyopia and nystagmus or hearing impairments are also very common. As a result, learning difficulties, as well as hyperkinesia and inattention are usually present in children with cerebral palsy. Furthermore, 
people with cerebral palsy have orientation and balance problems, difficulties in perception of space and time and disturbances in tactile sensation. However, the most common disorder that is associated with cerebral palsy is epilepsy, as it is observed in a large amount of cases, in up to 50\% - 60\% (Kurtz \& Scull, 1993, Gersh, 1998).

Last but not least, psychological and psychiatric disorders are also very often. Their disability obliges them to depend on others in order to accomplice their everyday activities, and as a result they feel disappointed all the time (Spetsiotis \& Stathopoulos, 2006). As if it was not enough, the way society treats them makes them feel embarrassed and inferior. In many cases people with cerebral palsy have behavioral problems (Stroulia, 2001) or even worse, they may be diagnosed with schizophrenia or depression (Papadopoulou, 2013).

Many researchers state that quality of life is directly related to health (Aaronson et al., 1992, WHO, 2011). Vargus-Adams (2005) studied the quality of life of children with cerebral palsy in correlation with the seriousness of their health condition, using the "Child Health Questionnaire". The results of her research showed that, according to their parents' opinion, children with cerebral palsy have low quality of life.

In another research, Wiley and Renk (2007) used "The Lifestyle Assessment Questionnaire" and "The Caregiver Questionnaire" and came to the conclusion that the factors that affect the quality of life of children with cerebral palsy are their parents' stress, their depressive syndromes that they possibly have and their behavioral problems.

Additionally, some researchers studied the quality of life of adults with cerebral palsy. Such research is the one that Gaskin and Morris carried out in 2008. They found that the health-related quality of life of people with cerebral palsy is very low because of their small participation in physical activities. Furthermore, a research that took place in Germany and Sweden, showed that the levels of their well-being are not low, but there are differentiations depending on their social integration (Hergenroeder \& Blank, 2009).

On the other hand, in Greece, there are very few findings for the quality of life of people with cerebral palsy. One recent research that took place in 2010, investigated the quality of life of children with cerebral palsy. The tools of the research were "DCGM-37", "SMILEYS Questionnaire" and "Cerebral Palsy Module". The results showed that the quality of life of those children varies depending on the different questionnaires that were used, their age, their mental state and the seriousness of their cerebral palsy (Kosmetatou, 2010).

According to Antonovsky (1987: p. 19), sense of coherence (SOC) is a global orientation that expresses the extent to which one has a pervasive and enduring, though dynamic, feeling of confidence that: 1) the stimuli derived from one's internal and external environments in the course of living are structured, predictable and explicable (comprehensibility), 2) the resources are available to one to meet the demands posed by these stimuli (manageability) and 3) these demands 
are challenges that are worthy of investment and engagement. He believed that sense of coherence is connected to people's (mental) health and as a result it affects their quality of life. In 1979, he created the "Sense of Coherence Scale", a questionnaire of 13 questions, based on various sectors of life (Antonovsky, 1993). In 1996, T. Anagnostopoulou translated it in Greek, but it was also translated in 32 more languages and was used in 31 different countries. That proves the fact that it is a valid and reliable research tool regardless of the population of the research sample (Eriksson \& Lindstrom, 2005). Its validity and reliability have also been verified in Greece, with a research that took place in 2004 (Karalis et al., 2004).

Pallant and Lae's study in 2002 confirmed the current theory according to which sense of coherence is directly connected to physical and psychological well-being. A few years later in 2006, Eriksson and Lindstrom, who used Aaron Antonovsky's questionnaire (SOC Scale) in their research, concluded that the stronger the sense of coherence is, the higher the levels of mental health are. In addition, the following year, the results of another research that they also conducted, showed that sense of coherence and quality of life are linked to each other (Eriksson \& Lindstrom, 2007).

\section{Method}

\subsection{Research Design}

The main objective of this research was the evaluation of the Sense of Coherence (SOC) of people with Cerebral Palsy (comparative groups of participants with and without Intellectual Disability). In addition, there was an attempt to examine the correlation of SOC with their Quality of Life. For those purposes, a mixed methodological approach was used which employed both quantitative and qualitative methods.

\subsection{Sample \& Participants}

Purposeful sampling was used for the selection of the research sample. More specifically, 37 individuals with Cerebral Palsy, between the ages of 15 and 30, participated in the research. Also, the Special Educators who were responsible for teaching and implementing Curriculum Based Interventions to individuals with Cerebral Palsy, through structured interviews, participated in the research.

\subsection{Research Tools}

\subsection{1. "Sense of Coherence" Scale}

For the purposes of the research the Sense of Coherence Scale-SOC was used (Antonovsky, 1993). More specifically, a 13-item version of the scale was used, which evaluated through a 7 -point Likert scale $(1=$ very rarely/never, $7=$ very often). For the purpose of data collection, this the psychometric scale assessed to special educators employed at Open Door Centre of Education and Rehabilitation for people with Cerebral Palsy Greece. Likewise, the quantitative results 
were checked for their validity and reliability by calculating the Cronbach's alpha index. In this case, Cronbach's alpha was $0.889>0.500$ (Table 1), which means that the reliability index was exceptional high for the SOC Scale.

\subsubsection{Interview Guide}

Semi-structured interviews with special educators were conducted in order to evaluate the Sense of Coherence and Quality of Life in people with Cerebral Palsy.

\subsubsection{Peer Observation}

Moreover, the methodological technique of observation was used. More specifically, there was a peer observation of 5 individuals with Cerebral Palsy.

\section{Data Analysis}

\subsection{Quantitative Analysis-Statistical Tools}

In social sciences, the most common statistical tool is SPSS (Statistical Package for Social Sciences). In this research, IBM SPSS Statistics, Version 19.0.0. was utilized for the quantitative data analysis.

\subsection{Qualitative Analysis}

For the purposes of this research, Qualitative Analysis was implemented by using inductive thematic analysis.

\section{Results}

\subsection{Quantitative Results}

\subsubsection{Analysis of the Sense of Coherence Scale-Score (SOC-Score)}

The Sense of Coherence Scale was examined for its data normality by utilizing the Kolmogorov-Smirnov Test (Table 2), which is designed to check the sample's distribution. The test showed that the sample's distribution does not differ from the regular distribution ( $p$-value $=0.2$ ), with the significance level at $\mathrm{a}=$ $5 \%$.

The calculation of the Sense of Coherence Scale-Score (SOC-score) for each person of the sample was made by the answers given in the questionnaire, which is based on Likert scale. Each of the 13 questions has 7 possible answers (1

Table 1. Cronbach's alpha in the sense of coherence scale.

\begin{tabular}{ccc}
\hline Cronbach's Alpha in the Sense of Coherence Scale & Cronbach's Alpha & Individuals (N) \\
\hline
\end{tabular}

Table 2. Regularity variables checks.

\begin{tabular}{ccccccc}
\hline & \multicolumn{3}{c}{ Kolmogorov-Smirnov } & \multicolumn{3}{c}{ Shapiro-Wilk } \\
\cline { 2 - 7 } & Statistic & Df & Sig. & Statistic & df & Sig. \\
\hline SOC-score & 0.075 & 37 & 0.200 & 0.982 & 37 & 0.787 \\
\hline
\end{tabular}


$=$ very rarely/never, $7=$ very often). In order to ensure the validity and accuracy of the calculation, Likert scale has been reversed for the questions with negative answers. The possible rates of the SOC-score are 13 - 91 and the mean is 52. In the population of this particular sample, the rate range of the SOC-score is 13 78 , while the mean is 43.7 , the median 46 , the st. deviation 16.3 , with skewness 0.055 and kurtosis -0.455 (Table 3 ).

Continuing, Table 4 shows the SOC-score that corresponds to each person of the sample $(13$ - 78). At this point, it is essential to underline that smaller SOC-score means higher level of sense of coherence. As it was mentioned before, the rate range of the SOC-score is 13 - 91 and the mean is 52 . So, we assume that those who scored less than 52 in the SOC Scale, also scored higher levels of sense of coherence and those who scored more than 52, belong to the group that displays lower levels of sense of coherence.

Table 4 indicates that the majority of the sample population scored less than $52(70.27 \%)$ and so the levels of their sense of coherence are high. However, $24.32 \%$ of the whole sample scored more than 52 and they are considered to have lower levels of sense of coherence, while there is a small percentage of only $5.41 \%$ who scored exactly 52 .

\subsubsection{Results of Descriptive Statistics Demographic Data}

\section{1) Gender}

Concerning the demographic data of the participating people with cerebral palsy, $62.2 \%$ of the sample population was male (23/37 people) and $37.8 \%$ female (14/37 people).

In order to examine whether there is a difference in SOC-score between the two genders, the statistical criterions of Mann-Whitney $U$ test were used. It

Table 3. Statistical analysis of the SOC-score.

\begin{tabular}{ccc}
\hline & Valid & 37 \\
\cline { 3 - 3 } & Missing & 0 \\
\hline Mean & 43.7027 \\
Mode & 46.0000 \\
Std. Deviation & 50.00 \\
Variance & 16.34840 \\
Skewness & 267.270 \\
Std. Error of Skewness & .055 \\
Kurtosis & .388 \\
Std. Error of Kurtosis & -.455 \\
Range & .759 \\
Minimum & 65.00 \\
Maximum & 13.00 \\
\hline
\end{tabular}


Table 4. SOC-score for each participant.

\begin{tabular}{|c|c|c|c|}
\hline Code-number of each participant & SOC-score & Code-number of each participant & SOC-score \\
\hline 1 & 49 & 20 & 50 \\
\hline 2 & 29 & 21 & 65 \\
\hline 3 & 46 & 22 & 53 \\
\hline 4 & 54 & 23 & 13 \\
\hline 5 & 35 & 24 & 27 \\
\hline 6 & 50 & 25 & 28 \\
\hline 7 & 47 & 26 & 23 \\
\hline 8 & 26 & 27 & 37 \\
\hline 9 & 48 & 28 & 52 \\
\hline 10 & 72 & 29 & 34 \\
\hline 11 & 50 & 30 & 58 \\
\hline 12 & 43 & 31 & 67 \\
\hline 13 & 46 & 32 & 31 \\
\hline 14 & 43 & 33 & 63 \\
\hline 15 & 52 & 34 & 22 \\
\hline 16 & 40 & 35 & 13 \\
\hline 17 & 40 & 36 & 71 \\
\hline 18 & 42 & 37 & 20 \\
\hline 19 & 78 & & \\
\hline
\end{tabular}

appeared that there is no statistically significant difference between them ( $\mathrm{Z}=$ $-0.736, p$-value $=0.462)$ and the significance level was determined at $a=5 \%$.

\section{2) Age}

The average age of the sample population was $24.1 \pm 4.5$ years.

Because of the differentiation that is observed between the distribution of age in the sample population and the regular age distribution, it was essential that the Spearman's non parametric correlation was calculated (Spearman's rho). The result showed that there is no statistically significant correlation between SOC-score and age $($ rho $=0.129, p$-value $=0.447)$.

\section{3) Cerebral Palsy Type}

Regarding the type of cerebral palsy, $43.2 \%$ of the population of the sample has quadriplegia ( $16 / 37$ people), $21.6 \%$ has diplegia ( $8 / 37$ people), $13.5 \%$ has hemiplegia ( $5 / 37$ people), another $13.5 \%$ has paraplegia ( $5 / 37$ people), $5.4 \%$ has monoplegia ( $2 / 37$ people) and only $2.7 \%$ has triplegia ( $1 / 37$ people).

Using the one-way analysis of variance (one-way ANOVA) showed that there is no statistically significant differentiation in SOC-score between people with different types of cerebral palsy $(\mathrm{F}=0.258, p$-value $=0.933)$, with the significance level at 5\% (Table 5). 


\section{4) Associated Deficits}

The majority of the participators $(70.27 \%)$ do not seem to have visual or hearing impairments, but they do have speech disorders (62.16\%) and learning difficulties (97.30\%). Also, a large part of the sample population is diagnosed with mental retardation (83.78\%), while only $29.73 \%$ are epileptic and $35.14 \%$ suffer from psychological-psychiatric disorders.

In order to check whether there are differentiations in SOC-score, in correlation with the associated deficits of the sample, the non-parametric Mann-Whitney U test was utilized (Table 6). The results of the test showed that there are statistically significant differences in SOC-score in people with speech disorders $(p$-value $=0.022)$, with the significance level at $5 \%$. The average SOC-score of those people is almost 38.9, while of those who do not have speech disorders it is 51.6. This means that people whose cerebral palsy is accompanied by speech disorders are more likely to score higher levels of sense of coherence.

On the contrary, in the population of the sample who suffer from psychological-psychiatric disorders, the results showed exactly the opposite. More specifically, the average SOC-score of people with cerebral palsy without psychological-psychiatric disorders is 39.4 and so they score higher levels of sense of

Table 5. SOC-score according to the cerebral palsy type (one-way ANOVA).

\begin{tabular}{|c|c|c|c|c|c|c|c|c|c|c|}
\hline & & \multirow{2}{*}{$\mathrm{N}$} & \multirow{2}{*}{ Mean } & \multirow{2}{*}{ St. Deviation } & \multirow{2}{*}{ St. Error } & \multicolumn{2}{|c|}{$95 \%$ confidence interval for mean } & \multirow{2}{*}{ Minimum } & \multirow{2}{*}{ Maximum } & \multirow{2}{*}{$\begin{array}{l}\text { Between- } \\
\text { Component } \\
\text { Variance }\end{array}$} \\
\hline & & & & & & Lower Bound & U er Bound & & & \\
\hline & Monoplegia & 2 & 39.0000 & 14.14214 & 10.00000 & -88.0620 & 166.0620 & 29.00 & 49.00 & \\
\hline & Hemiplegia & 5 & 46.4000 & 7.09225 & 3.17175 & 37.5938 & 55.2062 & 35.00 & 54.00 & \\
\hline & Diplegia & 8 & 47.5000 & 12.71669 & 4.49603 & 36.8686 & 58.1314 & 26.00 & 72.00 & \\
\hline & Triplegia & 1 & 40.0000 & . & . & . & . & 40.00 & 40.00 & \\
\hline & Quatriplegia & 16 & 43.6250 & 17.86197 & 4.46549 & 34.1070 & 53.1430 & 13.00 & 78.00 & \\
\hline & Paraplegia & 5 & 37.8000 & 27.01296 & 12.08056 & 4.2590 & 71.3410 & 13.00 & 71.00 & \\
\hline & Total & 37 & 43.7027 & 16.34840 & 2.68766 & 38.2519 & 49.1535 & 13.00 & 78.00 & \\
\hline \multirow{2}{*}{ Model } & Fixed Eft & & & 17.26244 & 2.83793 & 37.9147 & 49.4907 & & & \\
\hline & Random E & & & & 2.83793 & 36.4076 & 50.9978 & & & -41.16827 \\
\hline
\end{tabular}

Table 6. SOC-score according to the associated deficits.

\begin{tabular}{ccccccc}
\hline Associated Deficit & No N & Yes N & Mann-Whitney U & Wilcoxon W & Z & $p$-value (2-tailed) \\
\hline Visual and Hearing Impairments & 26 & 11 & 121,000 & 472,000 & -0.731 & 0.465 \\
Speech and Language Disorders & 14 & 23 & 88,000 & 364,000 & -2.287 & 0.022 \\
Learning Difficulties & 1 & 36 & 12,000 & 678,000 & -0.562 & 0.574 \\
Sensation Disorders & 27 & 10 & 115,000 & 170,000 & -0.684 & 0.494 \\
Intellectual Disability & 6 & 31 & 74,500 & 570,500 & -0.763 & 0.446 \\
Epilepsy & 26 & 11 & 120,000 & 186,000 & -0.765 & 0.444 \\
Psychological-Psychiatric Disorders & 24 & 13 & 90,000 & 390,000 & -2.101 & 0.036 \\
\hline
\end{tabular}


coherence, while the SOC-score of those who do have psychological-psychiatric disorders is 51.6 and their sense of coherence is on lower levels ( $p$-value $=$ 0.036).

For the rest of the associated deficits of people with cerebral palsy in the sample, statistically significant differentiations in SOC-score were not observed.

\subsubsection{Results of the Sense of Coherence Scale answering the Research Questions}

According to the data collected from the questionnaire, it appeared that the majority of people with cerebral palsy are satisfied with their everyday life. More specifically, only $16.22 \%$ of the sample population often have unpleasant feelings, such as pain or boredom, while the rest $83.78 \%$ very rarely or never have similar feelings. Results of the SOC Scale analysis showed that most of the people with cerebral palsy are able to control their feelings. According to the answers given in question no $13,67.57 \%$ of the samples rarely have feelings that they are not sure they can control. Also, people with cerebral palsy are not easily disappointed by important people in their life. Only a small amount of the sample (13.51\%) often feel disappointed by people they were counting on and likewise, only $18.92 \%$ of them often feel that they are being treated unfairly. The data collected from the SOC Scale showed that $78.38 \%$ of the sample populations rarely seem to deviate from their goals but these findings are not enough to give a definite answer whether people with cerebral palsy have clear goals in their life.

Moreover, only $24.32 \%$ of the samples often feel that they are in an unknown situation and they do not know what to do. As a result, it seems that the biggest amount of people with cerebral palsy is able to manage unknown situations. The SOC Scale analysis depicted that $16.22 \%$ of the research sample rarely have unpleasant feelings, such as pain or boredom, while 59.46\% rarely feel confused. Also, 35.14\% of them often have feelings that they would rather not have and only $18.92 \%$ have felt wasted in the past. As a conclusion, it seems that the feelings that people with cerebral palsy usually have in their everyday life are pleasant.

\subsection{Qualitative Results}

Based on the qualitative analysis of the data collected from the semi-structured interviews and the participatory observation, people with cerebral palsy are, in general, satisfied with their everyday life. Their favorite activities are, among others, drawing, listening to music, using the computer and playing video games, while others have more unusual interests, such as a small rope with balls. They seem very happy when they spend time with their teachers and they go for a walk or when they do other activities with them they follow their instructions with joy and are very dedicated to their duties. One remarkable finding is that most of them express their huge need for personal contact and many times, they seem to be obsessed with a particular person. As a result, they are quite satisfied when they have their undivided attention, but they feel frustrated when they do 
not. The few occasions that cause them unpleasant feelings are when they feel neglected, when they do not get what they want or when they have to deal with a change in their schedule and the routine they are used to. In these occasions, they feel nervous, sad and angry. They choose to stay alone and nobody can easily cheer them up. However, the majority of people with cerebral palsy has pleasant feelings and seems quite satisfied with their life, but there are some who do not seem to be able to communicate at all, they do not express any feelings and so it is very difficult for anyone to understand how they feel.

Many of the people with cerebral palsy find it difficult to control their feelings, especially their anger and anxiety. They hate surprises and all kinds of change, they cannot handle it when they feel neglected and when they do not get the attention they need and they do not like it when they are being treated unfairly, when they fail and when they have to deal with an unknown situation. In these occasions, they often cry and yell like babies. Sometimes, they are not able to define a situation and they overreact. Many of them misunderstand what people say and others feel nervous when someone of their close environment is absent. They believe that something bad has happened to them or they blame themselves. On the other hand, there are some exceptions who seem to have full control of their feelings and are able to handle every situation.

According to the data collected from the semi-structured interviews, the majority of people with cerebral palsy are easily disappointed by important people in their lives, such as their family, their teachers or their boyfriend/girlfriend, especially when they do not get the attention they need from them. Many times they have obsessions with those people and so they often feel neglected and sad. Also, it is difficult for them to understand when somebody is joking and they usually feel insulted. Some other times, they do not like it when someone scolds them and they think that they are being treated unfairly. In these occasions, they seem confused and they often burst into tears or they display immature behavior, while others get really angry and yell.

However, during the participatory observation, the data collected were not enough to give a clear picture about whether people with cerebral palsy are easily disappointed by important people in their life. There was only an incident in which only one person of the sample seemed very disappointed and frustrated when his teacher asked him to stop disturbing the lesson and stop bothering the rest of the team by making fuss. His reaction was to hide his head under the table.

The qualitative data were not enough to give an answer to this particular question, but in general, we can say that people with cerebral palsy do not seem to have clear goals in their lives.

People with cerebral palsy find it very difficult to manage an unknown situation and they usually feel anxious, nervous and confused. They cannot handle any kind of change in their schedule or when they meet a stranger.

For example, during the participatory observation of the researcher who was a 
stranger to them, some seemed surprised and shocked, while others were very shy and were trying to hide. However, people with cerebral palsy are generally social people and willing to communicate, even with people they do not know.

The majority of people with cerebral palsy is usually happy and seems to enjoy their everyday life. On the other hand, sometimes, they get confused, angry or sad, especially when they feel neglected or when they fail. They often blame themselves and their health condition for the way others treat them and believe that they deserve to be alone.

However, an interesting finding of the participatory observation was the fact that people with cerebral palsy who are not diagnosed with mental retardation are fully aware of their health condition and have accepted it, but at the same time, they feel quite sad when they compare themselves with those who do not have cerebral palsy and express their disappointment and complaints about the difficulties that they have to deal with in their life.

\section{Discussion}

The results of the present study showed that $70.27 \%$ of the people with cerebral palsy who participated in the research procedure display high scores of sense of coherence. Considering the results of similar researches that took place a few years earlier (Pallant \& Lae, 2002, Eriksson \& Lindstrom, 2006, Eriksson \& Lindstrom, 2007), they have good quality of life as well, since those two concepts (sense of coherence and quality of life) are directly connected with each other. Nevertheless, there are studies, which came to the opposite conclusion (Vargus-Adams, 2005, Gaskin \& Morris, 2008). Those researches concluded that the quality of life of people with cerebral palsy is not so good, because of their bad health condition.

However, according to Wiley and Renk (2007), cerebral palsy is often followed by depressive syndromes. They believe that these syndromes affect the quality of life of children with cerebral palsy. Likewise, in the present research, the statistical analysis of the "SOC Scale" indicated that people with cerebral palsy who do not have psychological-psychiatric disorders, display higher levels of sense of coherence and so their quality of life is better.

The present study also concluded that there is not a statistically important difference in the sense of coherence between people with different kind of cerebral palsy. Another research that took place a few years earlier concluded to similar results (Arnaud et al., 2008). In addition to this, Hergenroeder and Blank (2009), who studied the well-being of people with cerebral palsy, also believed that in general terms, those people are satisfied with their life. This belief is totally identical to the answer given in the first research question. According to the collected data, the well-being of the majority of people with cerebral palsy ranges at high levels.

Finally, it is essential to note that in Greece, the existing knowledge of this specific topic is limited. Only one research investigated the quality of life of 
children with cerebral palsy, 4 - 12.5 years old (Kosmetatou, 2010). Its results showed that the quality of life of those children varies depending on the different questionnaires that were utilized, their age, their mental state and the seriousness of their health condition. On the contrary, in the present research, the quality of life of the sample (adolescents and adults 15 - 30 years old) did not seem to differ depending on their age, their mental state or the seriousness of their health condition. Differentiations were noticed only in people with psychological-psychiatric problems or with speech disorders. Specifically, it seems that people with cerebral palsy who have also been diagnosed with speech disorders are more likely to display higher levels of sense of coherence, than those who do not have speech disorders. This finding is of particular interest and needs further investigation.

\section{Conclusion}

As a conclusion, the findings from the quantitative analysis of this research depict high scores of sense of coherence in the majority of people with cerebral palsy (70.27\%). Additionally, statistical analysis also helped in giving answers to the research questions. In more detail, results state that the majority of these people are satisfied with their everyday life, they can control their feelings, they are able to cope with unknown situations and they usually have pleasant feelings.

On the other hand, the majority of people with cerebral palsy have difficulties in controlling their feelings, especially their anger and anxiety. Respectively, results of the qualitative analysis showed that people with cerebral palsy, are easily disappointed, especially by people that they consider important. At the same time, they seem to be unable to cope with unknown situations.

Those differences can easily be explained if we consider that qualitative research methods are not supposed to be totally objective. This happens because they include the subjective opinions of the researcher and of those who participate in the research procedure (Paraskevopoulou-Kollia, 2008). In addition to the above, the population of the sample that was studied with qualitative methods was much smaller, namely only 7 of 37 people of the whole sample. Those 7 people happen to belong to the small part of $24.32 \%$, who, according to the SOC score, have low sense of coherence.

Finally, the fourth question could not be answered neither with qualitative data analysis. Research findings were not enough to answer that particular question.

\section{Study Limitations \& Future Propositions}

At this point, it is important to underline the fact that there are some limitations in every research. Initially, as many scientists believe, qualitative methods, like semi-structured interviews and participatory observation, are considered to be subjective methods (Paraskevopoulou-Kollia, 2008). Specifically, Cohen, Manion, \& Morrison (2011) state that especially interviews are influenced by the 
prejudices of the participants.

It is also essential to note that the sample of the research is not representative, because it is too small and limited to people between 15 and 30 years old, and also there was no control group comparison (Paraskevopoulos, 1993). At the same time, all participants belong to "Cerebral Palsy Centre of Education and Rehabilitation of Greece-Open Door" which means that data is collected from only one source. As a result, the findings of this particular study cannot and should not be generalized (Cohen, Manion, \& Morrison, 2011).

One more limitation of this research is the fact that those who completed the questionnaire were not the people with cerebral palsy themselves, while Blanchflower and Oswald (2004) point out that reports of behavior, personal characteristics, feelings etc., are accurate and valid, only if they are made by those who are being studied. Not to mention the fact that only one questionnaire about the sense of coherence was utilized in the research procedure and none about the quality of life. Therefore, it is not possible for these two concepts to be perfectly correlated with each other. Besides, quality of life is totally subjective (Dellasoudas, 2006).

However, the results of this research are valuable for the scientific society, because the existing knowledge about this subject was very limited until now. In the future, quality of life of people with cerebral palsy can be studied by using more tools-questionnaires, in order to come to a better and more valid conclusion. Each questionnaire should be completed by people without disabilities or with disabilities other than cerebral palsy, so as to be compared with each other. This will help in the improvement of the quality of life of people with disabilities in general.

\section{References}

Aaronson, N. K., Acquardo, C., Alonso, J., Apolone, G., Bucquet, D., Bullinger, M., Bungay, K., Fukuhara, S., Gandek, B., Keller, S., Razavi, D., Sanson-Fisher, F. L., Sullivan, M., Wood-Dauphinee, S., Wagner, A., \& Ware, J. E. (1992). International Quality of Life Assessment (IQOLA) Project. Quality of Life Research, 1, 349-351. https://doi.org/10.1007/BF00434949

Antonovsky, A. (1987). Unraveling the Mystery of Health: How People Manage Stress and Stay Well. San Francisco: Jossey-Bass.

Antonovsky, A. (1993). The Structure and Properties of the Sense of Coherence Scale. Social Science \& Medicine, 36, 725-733. https://doi.org/10.1016/0277-9536(93)90033-Z

Arnaud, C., White-Koning, M., Michelsen, S. I., Parkes, J., Parkinson, K., Thyen, U., Beckung, E., Dickinson, H. O., Fauconnier, J., Marcelli, M., MacManus, V., \& Colver, A. (2008). Parent-Reported Quality of Life of Children with Cerebral Palsy in Europe. Pediatrics, 121, 54-64. https://doi.org/10.1542/peds.2007-0854

Blanchflower, D. G., \& Oswald, A. J. (2004). Well-Being over Time in Britain and the USA. Journal of Public Economics, 88, 1359-1386.

http://wrap.warwick.ac.uk/315/1/WRAP_Oswald_finaljpubecwellbeingjune2002.pdf https://doi.org/10.1016/S0047-2727(02)00168-8

Bobath, B., \& Bobath, K. (1975). Motor Development in the Different Types of Cerebral 
Palsy. London: William Heinemann Medical.

Budden, S. (2005). Cerebral Palsy: Etiology and Classification. Asia-Pacific Childhood Disability Ubdate 2005.

Cohen, L., Manion, L., \& Morrison, K. (2011). Research Methods in Education (7th Edition). New York: Routledge.

Dellasoudas, L. G. (2006). Quality of Life of People with Disability. An Indicator of Social Inclusion and Integration (4th Part). Athens: Atrapos.

Eriksson, M., \& Lindström, B. (2005). Validity of Antonovsky's Sense of Coherence Scale: A Systematic Review. Journal of Epidemiology and Community Health, 59, 460-466. https://doi.org/10.1136/jech.2003.018085

Eriksson, M., \& Lindström, B. (2006). Antonovsky's Sense of Coherence Scale and the Relation with Health: A Systematic Review. Journal of Epidemiology and Community Health, 60, 376-381. https://doi.org/10.1136/jech.2005.041616

Eriksson, M., \& Lindström, B. (2007). Antonovsky's Sense of Coherence Scale and Its Relation with Quality of Life: A Systematic Review. Journal of Epidemiology and Community Health, 61, 938-944. https://doi.org/10.1136/jech.2006.056028

Evans, P. M., Evans, S. J. W., \& Alberman, E. (1990). Cerebral Palsy: Why We Must Plan for Survival. Archives of Disease in Childhood, 65, 1329-1333. https://doi.org/10.1136/adc.65.12.1329

Gaskin, C. J., \& Morris, T. (2008). Physical Activity, Health-Related Quality of Life, and Psychosocial Functioning of Adults with Cerebral Palsy. Journal of Physical Activity \& Health, 5, 146-157. https://doi.org/10.1123/jpah.5.1.146

Gersh, E. S. (1998). What Is Cerebral Palsy? In E. Geralis (Ed.), Children with Cerebral Palsy: A Parent's Guide (2nd Edition, pp. 1-34). Bethesda, MD: Woodbine House.

Hergenroeder, H., \& Blank, R. (2009). Subjective Well-Being and Satisfaction with Life in Adults with Spastic Cerebral Palsy: A Pilot Study of a Randomized Sample. Developmental Medicine \& Child Neurology, 51, 389-396.

https://doi.org/10.1111/j.1469-8749.2008.03169.x

Karalis, I., Langius, A., Tsirogianni, M., Faresjö, T., Nettelbladt, P., \& Lionis, C. (2004). The Translation-Validation of the Sense of Coherence Scale into Greek and Its Use in Primary Health Care. Archives of Hellenic Medicine, 21, 195-203.

Koman, L. A., Smith, B. P., \& Balakrishnan, R. (2003). Spasticity Associated with Cerebral Palsy in Children: Guidelines for the Use of Botulinum A Toxin. Pediatric Drugs, 5, 11-23. https://doi.org/10.2165/00128072-200305010-00002

Kosmetatou, E. (2010). Quality of Life of Children with Cerebral Palsy. PhD, Athens: Panteion University of Social and Political Sciences, Department of Sociology. http://thesis.ekt.gr/thesisBookReader/id/23007\#page/1/mode/2up

Kroustalakis, G. (2005). Children with Special Needs. Athens: Psychological-Educational Treatment.

Kurtz, L. A., \& Scull, S. A. (1993). Rehabilitation for Developmental Disabilities. Pediatric Clinics of North America, 40, 629-643. https://doi.org/10.1016/S0031-3955(16)38555-8

Leviton, A., Allred, E. N., Kuban, K. C. K., Hecht, J. L., Onderdonk, A. B., O’shea, T. M., \& Paneth, N. (2010). Microbiologic and Histologic Characteristics of the Extremely Preterm Infant's Placenta White Matter Damage and Later Cerebral Palsy. The ELGAN Study Pediatric Research, 67, 95-101.

Pallant, J. F., \& Lae, L. (2002). Sense of Coherence, Well-Being, Coping and Personality Factors: Further Evaluation of the Sense of Coherence Scale. Personality and Individual Differences, 33, 39-48. https://doi.org/10.1016/S0191-8869(01)00134-9 
Papadopoulou, E. (2013). Self-Esteem of Children with Special Needs. http://polispost.com/article/2989/i-aytoektimisi-sta-paidia-me-eidikes-\%20anagkes

Paraskevopoulos, I. (1993). Methodology of a Scientific Research (Volume A \& B). Athens: Athens.

Paraskevopoulou-Kollia, E. A. (2008). Methodology of Qualitative Research in Social Sciences and Interviews. Open Education-The Journal for Open and Distance Education and Educational Technology, 4.

Rosenbaum, P., Paneth, N., Leviton, A., Goldstein, M., Bax, M., Damiano, D., \& Jacobsson, B. (2007). A Report: The Definition and Classification of Cerebral Palsy April 2006. Developmental Medicine and Child Neurology. Supplement, 109, 8-14.

Sankar, C., \& Mundcur, N. (2005). Cerebral Palsy-Definition, Classification, Etiology and Early Diagnosis. Indian Journal Pediatric, 72, 865-868. https://doi.org/10.1007/BF02731117

Spetsiotis, I., \& Stathopoulos, S. (2006). Education and Teaching of Children with Motor Problems. Athens: Orion.

Stanley, F., Blair, E., \& Alberman, E. (2000). How Common Are the Cerebral Palsies? In Cerebral Palsies: Epidemiology and Causal Pathways Clinics in Developmental Medicine (No. 151, pp. 22-39). London: Mac Keith Press.

Stroulia, E. (2001). Self-Esteem and Social Support of Teenagers with Motor Disabilities. PhD, Athens: National and Kapodistrian University of Athens, Department of Phylosophy, Education and Psycology, Sector of Psychology.

Turner, R. J., \& Beiser, M. (1990). Major Depression and Depressive Symptomatology among the Physically Disabled: Assessing the Role of Chronic Stress. Journal of Nervous and Mental Disease, 178, 343-350. https://doi.org/10.1097/00005053-199006000-00001

Vargus-Adams, J. (2005). Health-Related Quality of Life in Childhood Cerebral Palsy. Archives of Physical Medicine and Rehabilitation, 86, 940-945.

https://doi.org/10.1016/j.apmr.2004.10.036

Wiley, R., \& Renk, K. (2007). Psychological Correlates of Quality of Life in Children with Cerebral Palsy. Journal of Developmental Physical Disability, 19, 427-447.

https://doi.org/10.1007/s10882-007-9041-0

World Health Organization, WHO (2011). Presentation: "Designing the Road to Better Health and Well-Being in Europe" at the 14th European Health Forum Gastein. http://www.euro.who.int/_data/assets/pdf_file/0003/152184/RD_Dastein_speech_well being_07Oct.pdf

World Health Organization, WHO (1993). Promoting the Development of Young Children with Cerebral Palsy, A Guide for Mid-Level Rehabilitation Workers. Geneva: World Health Organization. 